\title{
Sex differences in the association between marital status and the risk of cardiovascular, cancer, and all-cause mortality: a systematic review and meta- analysis of 7,881,040 individuals
}

Yafeng Wang ${ }^{1 \dagger}$, Yurui $\mathrm{JiaO}^{2 \dagger}$, Jing Nie ${ }^{3 \dagger}$, Adrienne $\mathrm{O}^{\prime} \mathrm{Neil}^{4}$, Wentao Huang ${ }^{5}$, Lei Zhang ${ }^{6}$, Jiafei Han ${ }^{7}$, Hao Liu ${ }^{8}$, Yikun Zhu' ${ }^{2}$ Chuanhua Yu ${ }^{1 *}$ and Mark Woodward9,10,11

\begin{abstract}
Purpose: To ascertain whether sex differences exist in the relationship between marital status and cardiovascular diseases (CVD), coronary heart disease (CHD), cancer and all-cause mortality in the general population and to explore the potential effect of age, location, the duration of follow-up and publication years on these outcomes.

Methods: A systematic search was performed in PubMed and EMBASE from inception through to April 2018 and review of references to obtain sex-specific relative risks and their $95 \%$ confidence intervals. These were used to derive the women-to-men ratio of RRs (RRR) and 95\% Cl for each study. RRs and RRRs for each outcome were then pooled using random effects inverse-variance weighted meta-analysis.

Results: Twenty-one studies with 7,891,623 individuals and 1,888,752 deaths were included in the meta-analysis. Compared with married individuals, being unmarried was significantly associated with all-cause, cancer, CVD and coronary heart disease mortalities for both sexes. However, the association with CVD and all-cause mortality was stronger in men. Being divorced/separated was associated with a higher risk of all-cause mortality in men and a stronger risk of cancer and CVD mortality. The pooled ratio for women versus men showed 31 and 9\% greater risk of stroke mortality and all-cause mortality associated with never married in men than in women.
\end{abstract}

Conclusions: Being unmarried conferred higher risk of stroke and all-cause mortality for men than women. Moreover, divorced/separated men had higher risk of cancer mortality and CVD mortality. Further studies are warranted to clarify the biological, behavioral, and/or social mechanisms involved in sex differences by these associations.

Keywords: Marital status, Sex difference, Mortality, Meta-analysis

\footnotetext{
* Correspondence: yuchua@whu.edu.cn

†Yafeng Wang, Yurui Jiao and Jing Nie contributed equally to this work.

'Department of Epidemiology and Biostatistics, School of Health Sciences,

Wuhan University, 185 Donghu Road, Wuchang District, Wuhan 430071,

China

Full list of author information is available at the end of the article
}

(c) The Author(s). 2020 Open Access This article is distributed under the terms of the Creative Commons Attribution 4.0 International License (http://creativecommons.org/licenses/by/4.0/), which permits unrestricted use, distribution, and reproduction in any medium, provided you give appropriate credit to the original author(s) and the source, provide a link to the Creative Commons license, and indicate if changes were made. The Creative Commons Public Domain Dedication waiver (http://creativecommons.org/publicdomain/zero/1.0/) applies to the data made available in this article, unless otherwise stated. 


\section{Background}

Marital status has been identified as an important social factor associated with mortality. In current epidemiologic research, being unmarried was observed to be a suboptimal health status in the global population [1]. In 2017, more than 45\% of Americans were unmarried and approximately 35.25 million people were living alone [2]. In China, the population of unmarried people has also steadily increased; reaching up to 218 million in the end of 2016, of which 129 million were men and 89 million were women [3]. The growing number of unmarried people has health implications, in light of evidence suggesting that it is associated with an increase in the incidence of various diseases and high mortality.

The beneficial effect of marriage on health is one of the most consistently positive findings in medical sociology and epidemiology [4]. Marriage offers a direct form of social support $[5,6]$ and it can reduce the risk of unhealthy behaviors such as poor diet or alcohol use [5-7]. In contrast, being unmarried has been suggested to contribute to less intimate social networks, loneliness and increased levels of stress hormones [8], which may increase risk from cardiovascular diseases (CVD) $[9,10]$, cancer $[11,12]$ or metabolic syndrome [13, 14]. While the links between marital status and CVD mortality risk have been widely reported [15-19], comparatively less has been observed regarding other conditions including cancer mortality and all-causes more broadly.

What also remains unclear is whether (and to what degree) specific types of non-marital statuses (widowed, divorced/separated or never married) are differentially associated with the aforementioned outcomes. Explicating these links are likely to be important in understanding the mechanisms that might underpin the relationship between marital status and disease risk, particularly as societal trends and attitudes towards marital status change. What is more, few attempts have been made to produce an overall estimate and sufficiently clarified of the sex difference between unmarried status and mortality risks, this is still a matter of debate. Evidence shows that men tend to benefit more from being married than do women with respect to their health [20-24]. A prospective register study of Finnish men and women found that living alone was a predictor of CVD mortality for men, while risk was higher for women who cohabitated [25]. Thus, it stands to reason that men would experience the greatest health losses in the absence of, or dissolution, of a marriage.

Therefore, we performed a meta-analysis of prospective cohort studies to ascertain the sex difference between marital status and CVD, cancer, all-cause mortality in the general population and to explore the potential effect of age, location, the duration of follow-up and publication years on these outcomes.

\section{Methods}

This meta-analysis was conducted in accordance with the MOOSE (Meta-analysis Of Observational Studies in Epidemiology) guidelines [26].

\section{Literature search strategy}

A systematic search was performed in PubMed and EMBASE from their inception (1966 and 1947, respectively) through to April 2018 using the key words "marital status", "married", "unmarried", "widowed", "divorced", "single", "separated", "mortality" and "prospective cohort studies". The detailed search strategies were shown in the Supplemental Material. Only papers published in English language were considered. In addition, we also scrutinized the references of all identified reports for other potentially relevant publications and relevant reviews. If the information of the studies were incomplete, we also contacted the author to obtain sufficient data.

\section{Study selection}

Studies were included in this meta-analysis that met the following inclusion criteria: (1) Being a prospective cohort study; (2) Evaluating the association between marital status and mortality by sex; (3) The included studies had at least two groups pertaining to marital status (e.g married and not married), and the marital status of those non-married was defined by a "no" response to the question, "Have you ever been married?", which included divorced/separated, widowed and never married (4) The outcomes of the studies included at least one of the following: all-cause mortality, cancer mortality, CVD mortality, CHD mortality and/or stroke mortality; (5) Providing information about the multiple-adjusted risk ratio (RR), odds ratio (OR) and hazard ratio (HR) as well as corresponding 95\% confidence interval (CI) of the association between marital status and mortality in men and women; (6) If more than one article was published that based on the same population, we included only the article that provided results with most recent data and the largest number of participants. The exclusion criteria were as follows: (1) studies that were matched cohort design; (2) the results of the studies were not adjusted for at least age. Moreover, we also used individual participant data from the US National Health Interview Surveys (1997 to 2009) which linked National Death Index records through December 31, 2011.

\section{Data extraction and risk of bias assessment}

Details on study characteristics (first author's last name, publication year, location and ethnicity, study design, duration of follow-up), information regarding the included population (population source, number of participants with the martial status of married and not 
married, mean age, number of men and women) and the data on the outcomes [(all-cause mortality, cancer mortality, CVD mortality, CHD mortality, and stroke mortality), ICD code (if available)] were extracted by two authors (YR J and JF H) from each identified study by using a standardized extraction sheet independently, with disagreements resolved by discussion. We also extracted sex-specific multiple-adjusted measures of relative risk (RR; or equivalents) and 95\% confidence intervals.

The quality of each study was estimated according to the NOS (Newcastle-Ottawa Quality Assessment Scale) [27], which consists of 3 variables of quality as follows: object selection ( 4 points), comparability ( 2 points), and exposure and outcome (3 points) and each satisfactory answer received one star. Nine stars represents the best. We considered the studies with a score of $\geq 6$ reflecting high quality, while $\leq 4$ to be of low quality (Supplement Table 1).

\section{Statistical analysis}

For each study, we obtained the sex-specific RR or equivalents for individuals who were not married or subcategories of the unmarried (i.e. divorced/separated, widowed or never married) vs individuals who were married and 95\% CIs. We log transformed these RRs or equivalents and computed women-to-men ratio of RRs (RRR) and 95\% CIs to compare the sexes directly. These RRRs were calculated for studies with multiple-adjusted estimates [28]. We subsequently pooled the differences across studies using random-effects meta-analysis weighted by the inverse of the variances of the log RRRs, and then back transformed the data to obtain the pooled women-to-men ratio of the RR (RRR). In addition, for the individual participant data from the NHIS (1997 to 2009) linked mortality data, we also assessed the RRs, women-to-men ratio of RRs (RRR) and 95\% CIs used the same method. We also pooled relative risks for men and women separately. For one study, which reported separate hazard ratios for men and women in different divorced/separated, widowed and single groups, we first used inverse variance weighted random-effects metaanalysis to generate a summary hazard ratio of not married or the subsets of unmarried for men and for women. In addition, only one or two of three types of marital status category (i.e. divorced/separated, widowed or never married), could not be combined as the estimates of not married. Heterogeneity between studies was evaluated by using the $\mathrm{Q}$ test and $\mathrm{I}^{2}$ statistic. The level of significance for the $\mathrm{Q}$ test was defined as $P<$ 0.10 . $\mathrm{I}^{2}$ statistic was used to estimate the percentage of variability between studies due to between-study heterogeneity. $\mathrm{I}^{2}$ values $\leq 50$ and $>50 \%$ indicated no and significant heterogeneity respectively $[29,30]$.
Sensitivity analyses were performed by location (Asian, European, American and others), mean age groups $(<60$ vs $\geq 60$ years), follow-up duration ( $<10$ vs $\geq 10$ years) and publication years (pre-2000, 2001-2010, post-2010) and by sex. Random-effects meta-regression analyses were used to assess whether the differences in the mean baseline age and mean follow-up duration contributed to heterogeneity among the studies. We used the Egger's test, Begg's test and funnel plots (of the natural log of the RRR against its standard error) to examine publication bias for all primary analyses, and trim and fill analysis to adjust the RRRs for the presence of publication bias when more than 5 articles were included [31]. All analyses were performed using Stata version 12.0. Twosided $P$ value smaller than 0.05 was considered statistically significant.

\section{Results}

\section{Study characteristics}

The flowchart of the process of study selection is shown in Fig. 1. Overall, 21 studies [20-22, 32-48] (20 studies were retained for inclusion and one additional study was provided with individual participant data) comprising 7 , 881,040 individuals were analyzed. The number of participants ranged from 3, 386 to $6,500,000$ among the studies, which were performed in 15 countries ( 9 studies from Europe, 6 from Asia, and 6 from America). Moreover, 20 studies reported data on all-cause mortality (7, 846,939 participants, 1,887,151 deaths), 6 studies on cancer mortality $(7,081,927$ participants, 165,826 deaths $), 7$ studies on CVD mortality (7,095,655 participants, 128, 961 deaths), 5 studies on CHD mortality (288,719 participants, 15,140 deaths), and 5 studies on stroke mortality (583, 148 participants, 49,393 deaths). Individuals included in these studies were aged between 42.1 and 72.9 years old at baseline and the duration of study follow-up ranged from 5 to 29 years. The main characteristics of the included studies are summarized in Table 1.

\section{Marital status and all-cause mortality}

Compared with married individuals, the pooled RRs of all-cause mortality for non-married individuals were higher in both men and women (RR for men, 1.46, 95\% CI, 1.33-1.61, $P<0.001$; RR for women, 1.22, 1.12-1.33, $P<0.001$; Fig. 2). Moreover, non-married subgroups (divorced/separated, widowed and never married) had increased risk of all-cause mortality, compared with their married people (RR for divorced/separated group: men, $1.59,1.42-1.79$; women, 1.27, 1.13-1.42; RR for widowed group: men, 1.30, 1.23-1.38; women, 1.14, 1.05-1.24; RR for never married group: men, 1.67, 1.52-1.82; women, 1.46, 1.28-1.65; Supplemental Figure 1). The pooled multiple-adjusted women-to-men RRR of risk of allcause mortality associated with being unmarried was 


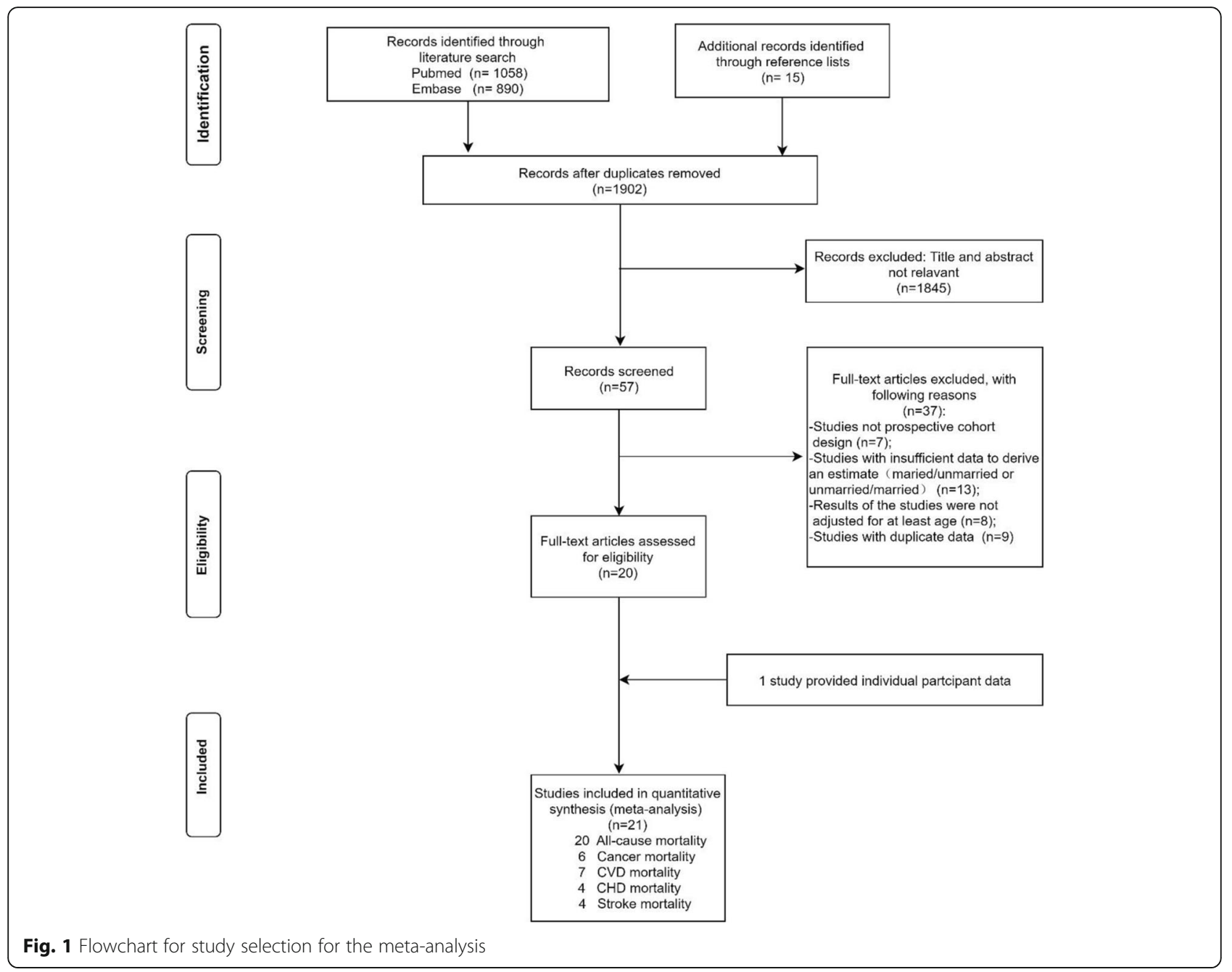

0.87 (0.79-0.94; $P=0.001$; Fig. 3; Fig. 4). Specifically, the risk of all-cause mortality for divorced/separated men was $18 \%$ higher than that for divorced/separated women (Women-to-men RRR, 0.82, 0.73-0.93, $P<0.001$; Supplement Figure 2) while the risk of all-cause mortality were $9 \%$ higher for widowed/never married men than for widowed/never married women (Both women-to-men RRRs, 0.91, 0.84-0.99, $P<0.05$; Supplement Figure 2).

\section{Marital status and cancer mortality}

Compared with married men and women, unmarried men and women had 12 and $9 \%$ higher risk of cancer mortality respectively (RR for men, 1.12, 1.09-1.14, $P<$ 0.001 ; RR for women, $1.09,1.01-1.18, P=0.03$; Supplement Figure 3). Compared with married men and women, divorced/separated men and women had 16\% (1.05-1.30) and 28\% (1.14-1.43; Supplement Figure 3) higher risk of cancer mortality respectively. However, there was no sex difference in widowed and never married groups (All $P>0.05$; Fig. 4). Additionally, being divorced/separated was associated with higher risk of cancer mortality in men than in women (Women-tomen RRR, 0.93, 0.90-0.96, $P<0.001$; Supplement Figure 4). No sex differences were found between not married, widowed and never married individuals (All $P>0.05$; Supplement Figure 4).

\section{Marital status and CVD mortality}

For CVD mortality, the risk was higher in non-married participants than in married participants (RR for men, 1.60, 1.39-1.84, $P<0.001$; RR for women, $1.19,1.01-1.42, P=$ 0.04; Supplemental Figure 5a), regardless of being divorced/ separated, widowed and never married (All $P<0.05$, Supplement Figure 5). Likewise, compared with unmarried women, unmarried men had a $20 \%$ greater risk of CVD mortality (RRR: 0.80, 0.72-0.89, $P<0.001$; Fig. 5). CVD mortality was greater in divorced/separated men than in divorced/separated women (women-to-men RRR: 0.85, 0.76$0.96, P=0.01$ ), but the risk is not significantly different between men and women who were widowed or never married (All $P>0.05$, Supplement Figure 6). In addition, although a similar association was also observed in 


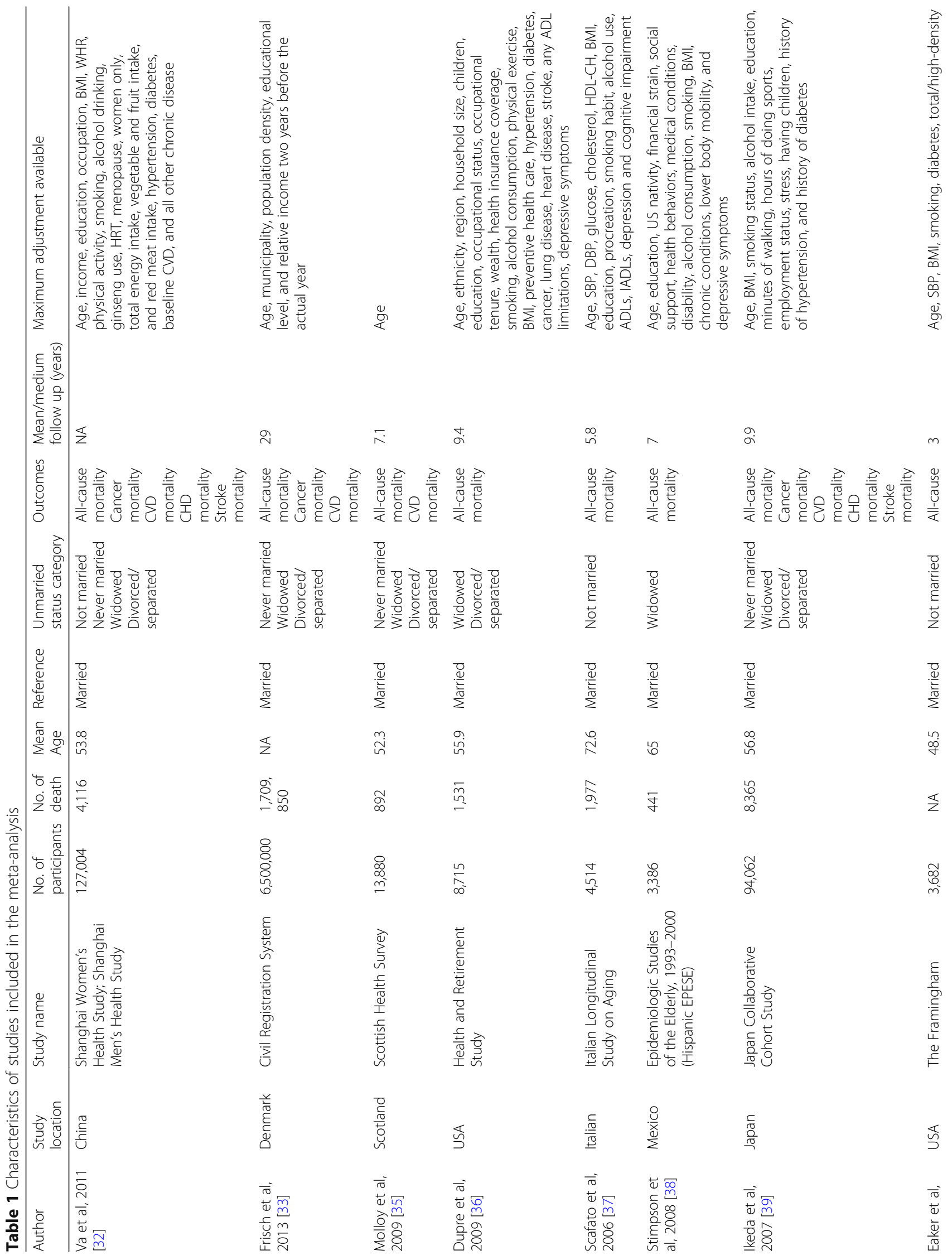




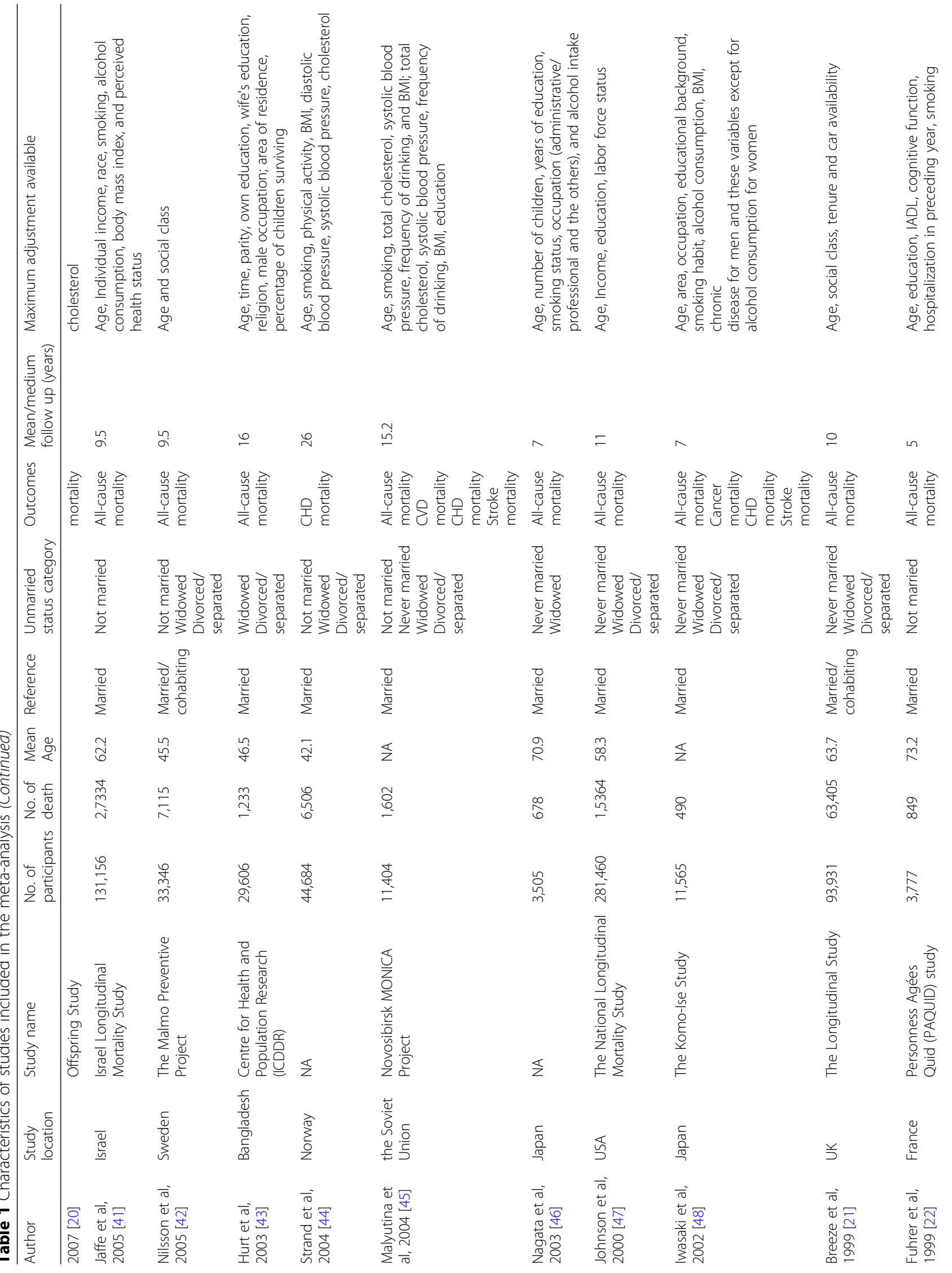




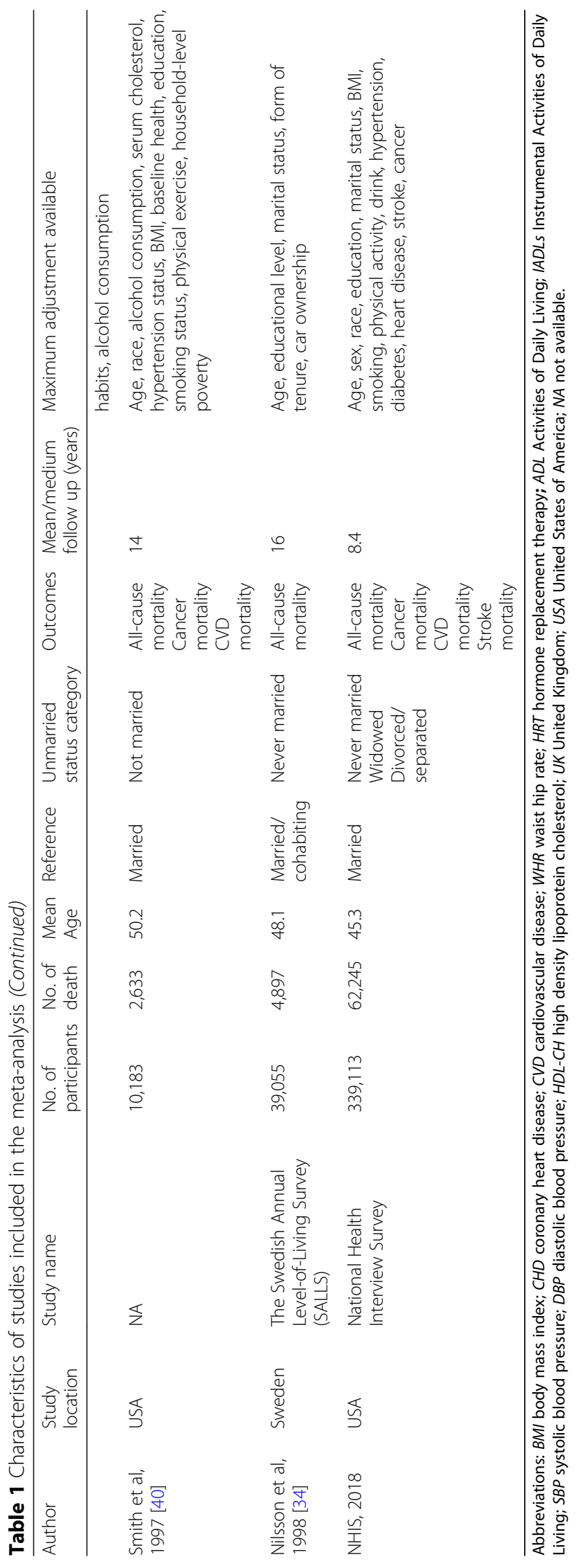




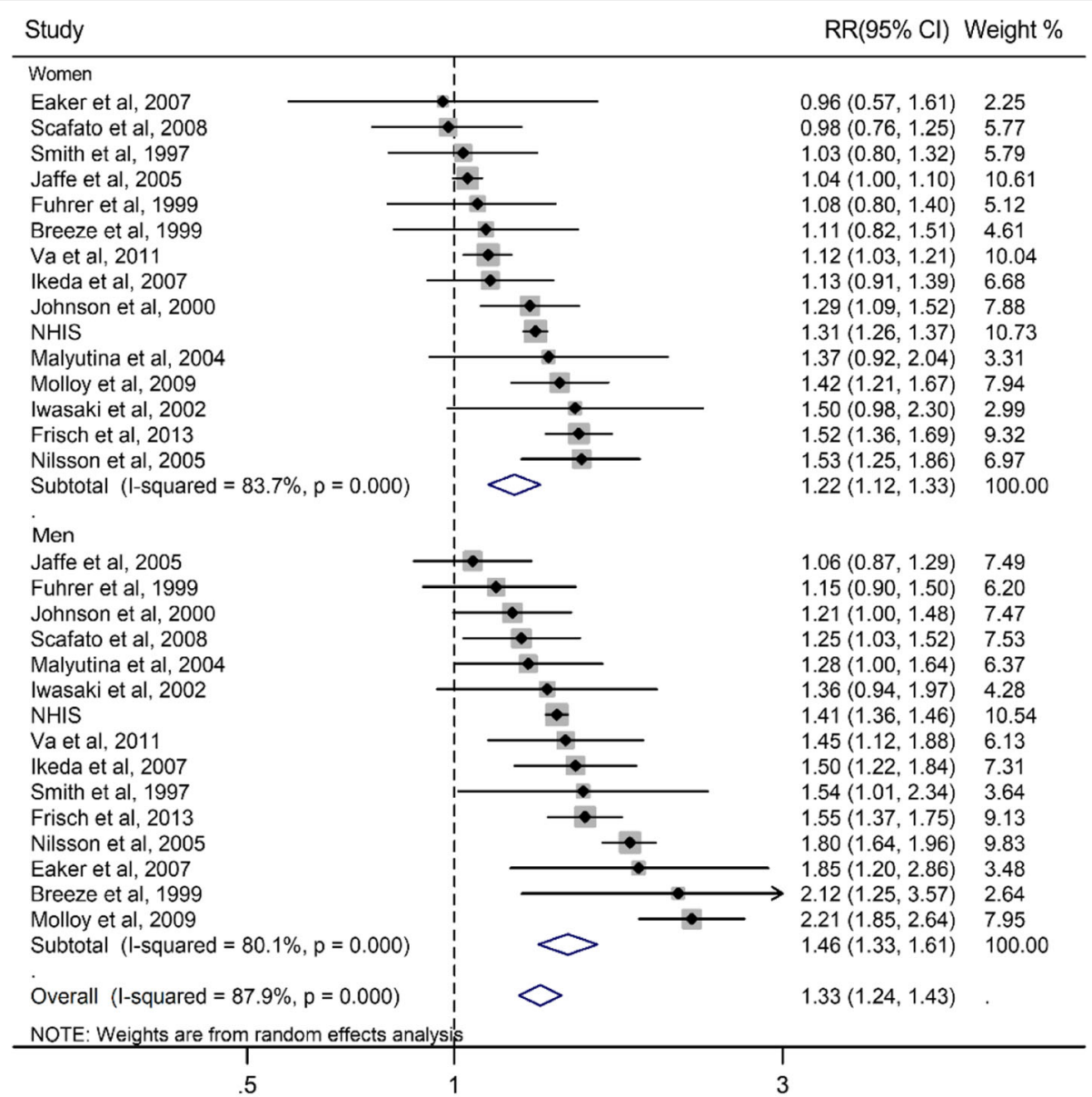

Higher RR in married

Higher RR in unmarried

Fig. 2 Sex-specific relative risks (RRs) for all-cause mortality, comparing non-married to married people. The boxes and lines indicate the RRs and their $95 \%$ confidence intervals (Cls) on a log scale for each study. The pooled odds ratio is represented by a diamond. The size of the gray squares indicate the relative weight of each estimate

CHD and stroke mortality, there were wider CIs because their sample size is probably small (Supplement Figures 7-10). Men who never married were at a $31 \%$ excess risk of stroke when compared with women who never married (Women-to-men RRR: 0.69, 0.471.00, $P=0.05$; Supplement Figure 10d).

\section{Meta-regression, subgroup analyses, sensitivity analyses and publication bias}

For all-cause mortality, meta-regression analyses indicated that the women-to-men RRR for all-cause mortality in the widowed group decreased by $2 \%$ for every year increase in mean age $(P=0.003$, Supplement Figure 11). It was also slightly associated with publication year and mean baseline age ( $\mathrm{P}$ for interaction <0.05; Supplement Figure 12; Supplement Table 3) but not correlated with study location or duration of follow-up (All $P>0.05$ ). Moreover, there was no effect of the duration of follow-up, location and the publication year of studies in participants who were unmarried, divorced/separated and never married for all-cause mortality (All $P>0.05$; Table 2). In addition, the sensitivity analyses removing each study one at a time, showed that the pooled estimates were not influenced by any single study, highlighting robustness of these findings.

Publication bias was found for CHD mortality in divorced/separated group (Egger's test $P=0.03$ ) and for all-cause mortality in widowed and never married groups (Both $P=0.003$; Supplement Figure 13); however, the trim-and-fill analysis did not change the overall results, and there was no evidence of publication bias for other endpoints (All $P>0.05$ ).

\section{Discussion}

This meta-analysis, which included data of more than 7 , 000,000 men and women, indicated that compared with being married, being unmarried was associated with 


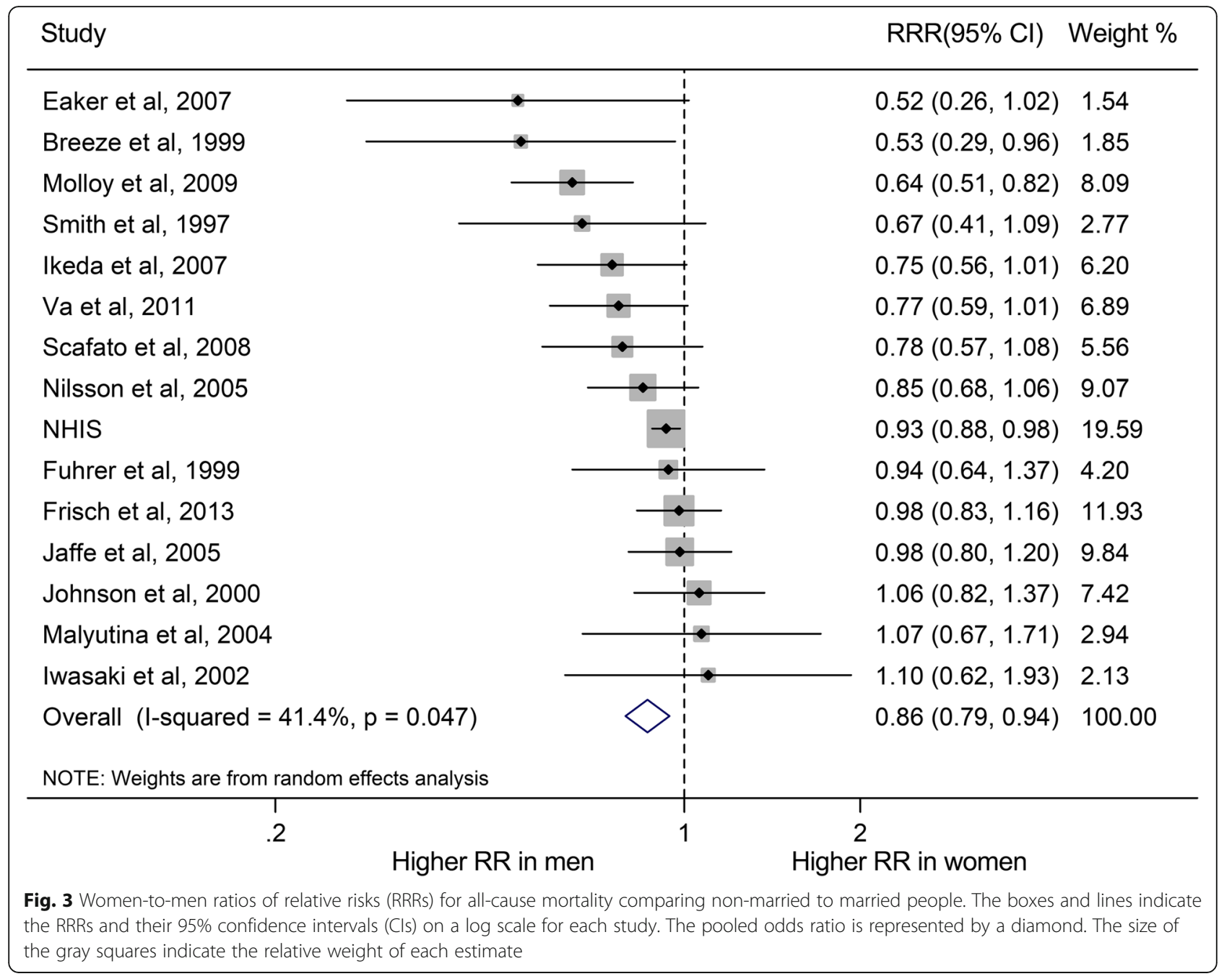

higher risk of all-cause mortality, cancer mortality, CVD mortality and CHD mortality. This was especially true for those who had never been married regardless of their gender. However, the association with death from allcause and CVD was stronger in men. Compared with women who were divorced or separated, men had higher risk of all-cause mortality, cancer mortality and CVD mortality after the dissolution of marriage. Moreover, men who never married were at 31 and 9\% separately higher excess risk of stroke mortality and all-cause mortality compared with never married women, but not CHD mortality.

Marital status appears to be a critical factor of mortality outcomes across different countries and cultures [23, 24]. A recent meta-analysis also showed that being unmarried was associated with increased risk of CHD death or stroke death in both men and women compared with married participants [19]. Compared with married people, unmarried individuals may obtain less emotional, financial and companionship support and can even experience more sub-clinical symptoms of depression and anxiety [49-51], and major mental disorder [52]. In addition, marriage selection theory proposes that healthier individuals were more likely to marry or stay married because of the physical and psychological advantageous attributes [53]. This may help explain why unmarried people had higher mortality than married people in the present study.

Our results showed that being unmarried is particularly more dangerous for men than for women with respect to CVD and all-cause mortality. This is consistent with findings from the previous meta-analysis which indicated that men who were single generally had the poorest health outcomes of any type among all unmarried conditions [54]. The potential mechanisms for such findings are likely to be biological, psychological and social in nature. From a biological standpoint, acute stressors which trigger activities of HypothalamicPituitary-Adrenal (HPA) axis and sympathetic nervous system $[8,35]$ and result in output of stress hormones 


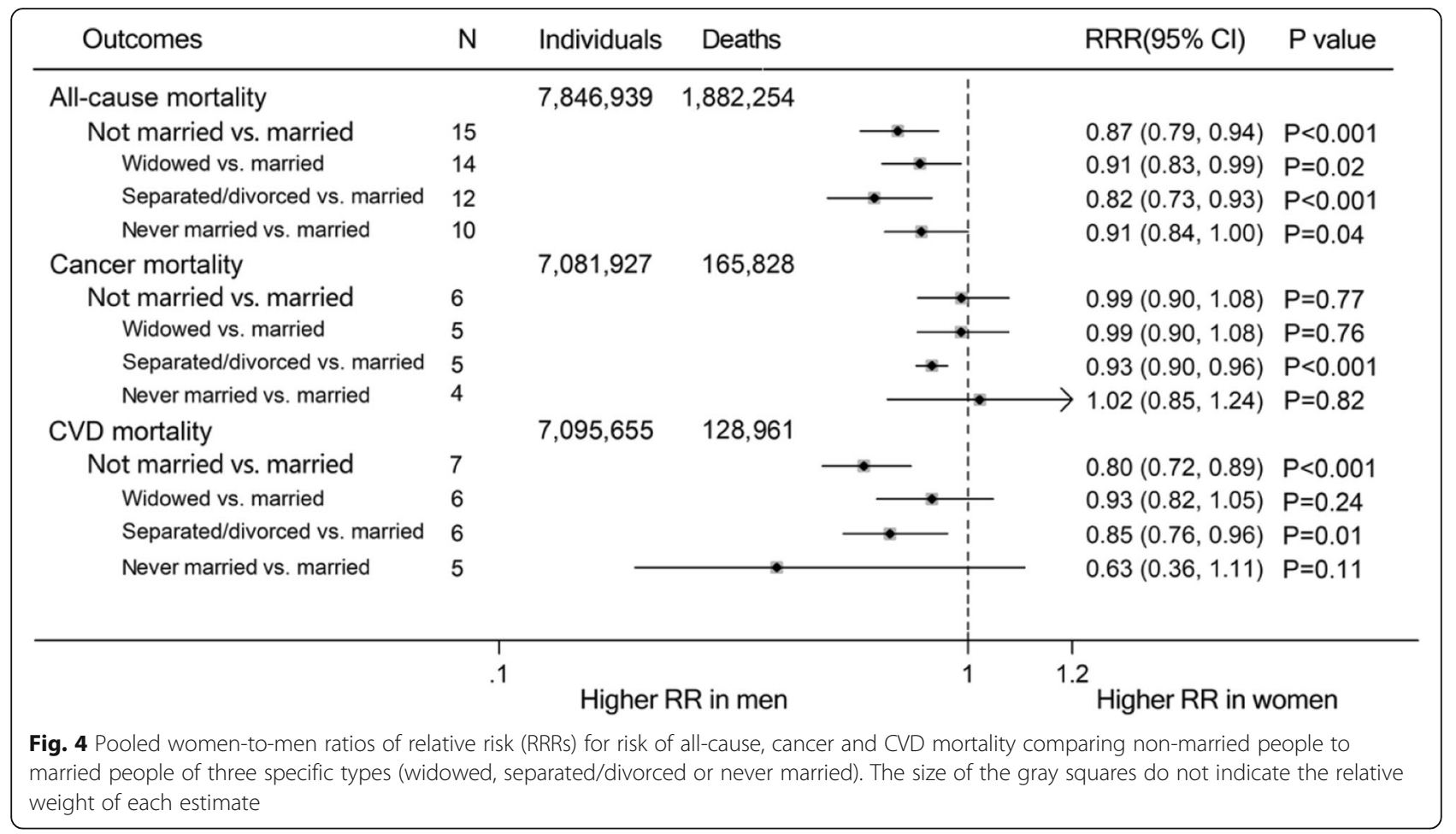

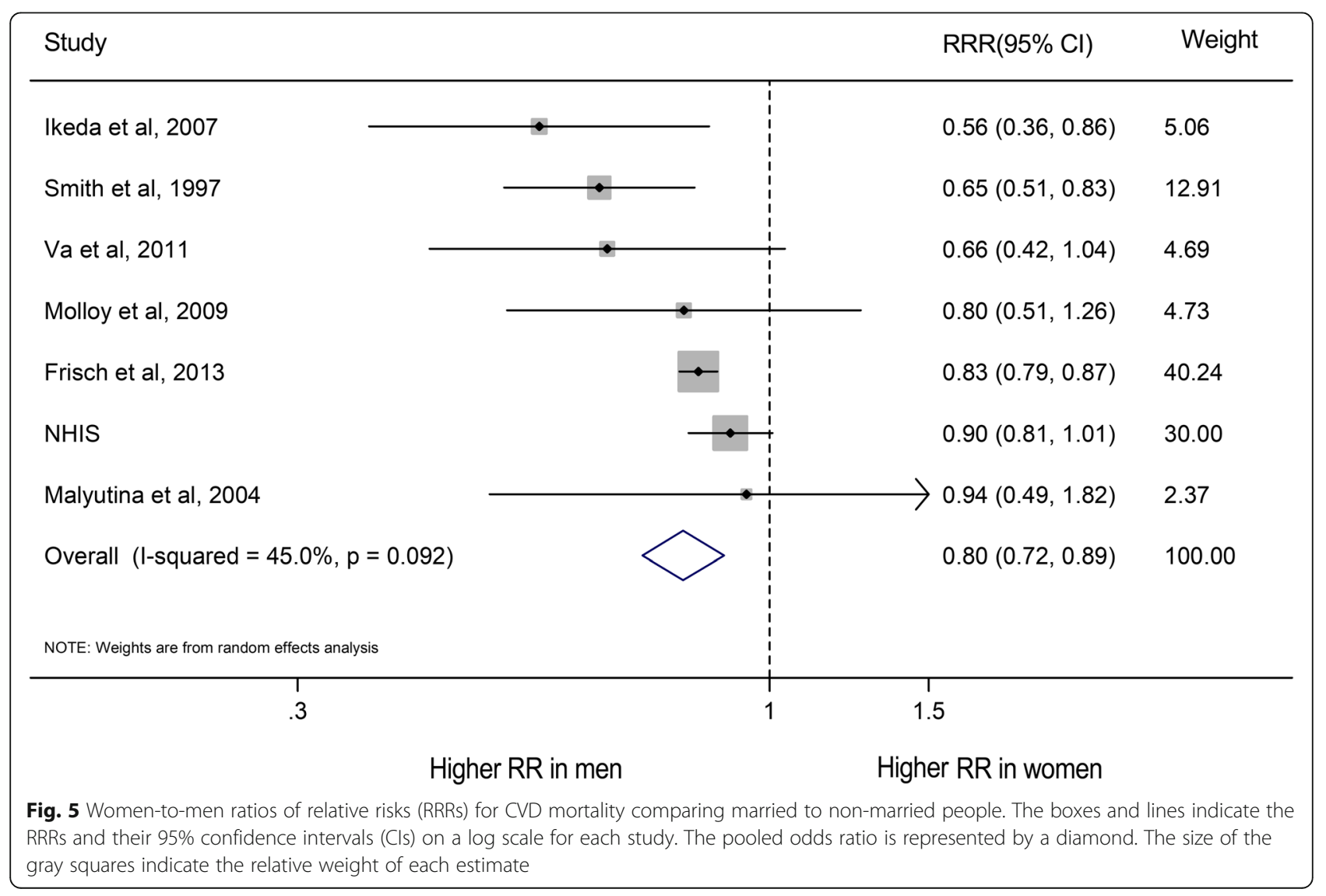


Table 2 Sensitivity analyses of women-to-men ratio of relative risks for all-cause mortality associated with marital status

\begin{tabular}{|c|c|c|c|c|c|c|c|c|c|c|}
\hline & \multirow[t]{2}{*}{ Individuals } & \multirow[t]{2}{*}{ N } & \multirow[t]{2}{*}{ RRR } & \multirow[t]{2}{*}{ Lower } & \multirow[t]{2}{*}{ Upper } & \multirow{2}{*}{$\begin{array}{l}P \\
\text { value }\end{array}$} & \multicolumn{3}{|c|}{ Test for heterogeneity } & \multirow{2}{*}{$\begin{array}{l}\text { P value } \\
\text { for } \\
\text { interaction }\end{array}$} \\
\hline & & & & & & & $P^{2}$ & $x^{2}$ & $P$ value & \\
\hline Unmarried vs. married & $7,659,086$ & 15 & & & & & & & & \\
\hline Age (years) & & & & & & & & & & 0.74 \\
\hline$<60$ & 775,733 & 7 & 0.82 & 0.70 & 0.95 & 0.01 & $63.10 \%$ & 16.24 & 0.01 & \\
\hline$\geq 60$ & 233,378 & 4 & 0.86 & 0.70 & 1.06 & 0.15 & $33.50 \%$ & 4.51 & 0.21 & \\
\hline Others & $6,649,973$ & 4 & 0.94 & 0.82 & 1.07 & 0.34 & $0.00 \%$ & 2.83 & 0.42 & \\
\hline Location & & & & & & & & & & 0.78 \\
\hline Asia & 363,787 & 4 & 0.87 & 0.74 & 1.02 & 0.09 & $19.50 \%$ & 1.7 & 0.29 & \\
\hline Europe & $6,660,861$ & 7 & 0.83 & 0.71 & 0.97 & 0.02 & $49.40 \%$ & 2.35 & 0.07 & \\
\hline America & 634,438 & 4 & 0.89 & 0.74 & 1.08 & 0.23 & $47.00 \%$ & 1.2 & 0.13 & \\
\hline \multicolumn{11}{|l|}{ Others } \\
\hline Follow-up years & & & & & & & & & & 0.30 \\
\hline$<10$ & 631,422 & 8 & 0.86 & 0.77 & 0.96 & 0.01 & $44.30 \%$ & 12.57 & 0.08 & \\
\hline$\geq 10$ & $7,027,664$ & 7 & 0.85 & 0.71 & 1.02 & 0.08 & $47.00 \%$ & 11.32 & 0.08 & \\
\hline Publication years & & & & & & & & & & 0.60 \\
\hline$\leq 2000$ & 389,351 & 4 & 0.84 & 0.63 & 1.12 & 0.22 & $50.60 \%$ & 6.07 & 0.11 & \\
\hline 2001-2009 & 303,618 & 8 & 0.82 & 0.71 & 0.95 & 0.01 & $39.60 \%$ & 11.59 & 0.12 & \\
\hline$\geq 2010$ & $6,966,117$ & 3 & 0.93 & 0.87 & 0.99 & 0.02 & $7.90 \%$ & 2.17 & 0.34 & \\
\hline Widowed vs. married & $7,654,572$ & 14 & & & & & & & & \\
\hline Age (years) & & & & & & & & & & 0.03 \\
\hline$<60$ & 915,181 & 7 & 0.90 & 0.80 & 1.01 & 0.07 & $54.20 \%$ & 13.11 & 0.04 & \\
\hline$\geq 60$ & 100,822 & 3 & 0.57 & 0.42 & 0.77 & $<0.001$ & $0.00 \%$ & 0.85 & 0.65 & \\
\hline Others & $6,638,569$ & 4 & 1.00 & 0.99 & 1.02 & $<0.001$ & $0.00 \%$ & 0.72 & 0.87 & \\
\hline Location & & & & & & & & & & 0.64 \\
\hline Asia & 265,742 & 5 & 0.88 & 0.76 & 1.02 & 0.09 & $54.20 \%$ & 5.69 & 0.22 & \\
\hline Europe & $6,652,570$ & 5 & 0.81 & 0.61 & 1.07 & 0.14 & $0.00 \%$ & 15.24 & $<0.001$ & \\
\hline America & 736,260 & 4 & 0.99 & 0.93 & 1.06 & 0.85 & $0.00 \%$ & 2.22 & 0.53 & \\
\hline Others & NA & & & & & & & & & \\
\hline Follow-up years & & & & & & & & & & 0.34 \\
\hline$<10$ & 611,167 & 8 & 0.84 & 0.73 & 0.98 & 0.03 & $55.30 \%$ & 15.66 & 0.03 & \\
\hline$\geq 10$ & $7,043,405$ & 6 & 0.94 & 0.81 & 1.09 & 0.43 & $55.00 \%$ & 11.12 & 0.05 & \\
\hline \multicolumn{11}{|l|}{ Publication years } \\
\hline$\leq 2000$ & 375,391 & 2 & 0.71 & 0.36 & 1.39 & 0.31 & $84.10 \%$ & 6.27 & 0.01 & 0.003 \\
\hline 2001-2009 & 313,064 & 9 & 0.84 & 0.76 & 0.92 & $<0.001$ & $0.00 \%$ & 7.71 & 0.46 & \\
\hline$\geq 2010$ & $6,966,117$ & 3 & 1.00 & 0.99 & 1.02 & 0.99 & $0.00 \%$ & 0.01 & 1.00 & \\
\hline Separated vs. married & $7,520,677$ & 12 & & & & & & & & \\
\hline Age (years) & & & & & & & & & & 0.60 \\
\hline$<60$ & 93,931 & 7 & 0.81 & 0.66 & 0.98 & 0.03 & $81.80 \%$ & 32.99 & $<0.001$ & \\
\hline$\geq 60$ & $6,649,973$ & 1 & 0.57 & 0.18 & 1.76 & 0.33 & NA & 0 & NA & \\
\hline Others & 776,773 & 4 & 0.79 & 0.50 & 1.24 & 0.31 & $69.80 \%$ & 9.93 & 0.04 & \\
\hline Location & & & & & & & & & & 0.75 \\
\hline Asia & 262,237 & 4 & 0.62 & 0.44 & 0.89 & 0.01 & $25.40 \%$ & 4.02 & 0.26 & \\
\hline Europe & $6,525,566$ & 5 & 0.77 & 0.57 & 1.04 & 0.08 & $88.10 \%$ & 33.71 & $<0.001$ & \\
\hline America & 732,874 & 3 & 0.97 & 0.83 & 1.13 & 0.68 & $61.70 \%$ & 5.23 & 0.07 & \\
\hline
\end{tabular}


Table 2 Sensitivity analyses of women-to-men ratio of relative risks for all-cause mortality associated with marital status (Continued)

\begin{tabular}{|c|c|c|c|c|c|c|c|c|c|c|}
\hline & Individuals & $\mathrm{N}$ & RRR & Lower & Upper & P & Test for & erogen & & \\
\hline & & & & & & & $\overline{1^{2}}$ & $x^{2}$ & $P$ value & $\begin{array}{l}\text { for } \\
\text { interaction }\end{array}$ \\
\hline Others & NA & & & & & & & & & \\
\hline Follow-up years & & & & & & & & & & 0.20 \\
\hline$<10$ & 604,276 & 6 & 0.73 & 0.59 & 0.90 & $<0.001$ & $76.70 \%$ & 21.48 & $<0.001$ & \\
\hline$\geq 10$ & $6,916,401$ & 6 & 0.93 & 0.76 & 1.15 & 0.50 & $65.20 \%$ & 14.36 & 0.01 & \\
\hline Publication years & & & & & & & & & & 0.94 \\
\hline$\leq 2000$ & 375,391 & 2 & 1.01 & 0.65 & 1.57 & 0.96 & $23.00 \%$ & 1.3 & 0.26 & \\
\hline 2001-2009 & 179,169 & 7 & 0.72 & 0.59 & 0.87 & $<0.001$ & $34.20 \%$ & 9.12 & 0.17 & \\
\hline$\geq 2010$ & $6,966,117$ & 3 & 0.89 & 0.80 & 1.00 & 0.05 & $80.20 \%$ & 10.12 & 0.01 & \\
\hline Never married vs. married & $7,511,483$ & 10 & & & & & & & & \\
\hline Age (years) & & & & & & & & & & 0.20 \\
\hline$<60$ & 767,579 & 5 & 0.89 & 0.81 & 0.97 & 0.01 & $22.40 \%$ & 5.16 & 0.3 & \\
\hline$\geq 60$ & 93,931 & 1 & 0.54 & 0.31 & 0.95 & 0.03 & NA & 0 & NA & \\
\hline Others & $6,649,973$ & 4 & 0.99 & 0.97 & 1.02 & 0.59 & $0.00 \%$ & 0.95 & 0.8 & \\
\hline Location & & & & & & & & & & 0.51 \\
\hline Asia & 232,631 & 3 & 0.87 & 0.66 & 1.15 & 0.31 & $0.00 \%$ & 1.62 & 0.44 & \\
\hline Europe & $6,658,279$ & 5 & 0.85 & 0.71 & 1.01 & 0.06 & $71.40 \%$ & 14.01 & 0.01 & \\
\hline America & 620,573 & 2 & 0.94 & 0.86 & 1.03 & 0.18 & $0.00 \%$ & 0.62 & 0.43 & \\
\hline Others & NA & & & & & & & & & \\
\hline Follow-up years & & & & & & & & & & 0.47 \\
\hline$<10$ & 447,064 & 3 & 0.93 & 0.83 & 1.04 & 0.07 & $40.20 \%$ & 3.34 & 0.19 & \\
\hline$\geq 10$ & $7,052,854$ & 6 & 0.84 & 0.70 & 1.02 & 0.21 & $50.20 \%$ & 10.04 & 0.07 & \\
\hline Others & 11,565 & 1 & 1.44 & 0.59 & 3.50 & 0.42 & NA & 0 & NA & \\
\hline Publication years & & & & & & & & & & 0.21 \\
\hline$\leq 2000$ & 414,446 & 3 & 0.86 & 0.69 & 1.08 & 0.19 & $58.20 \%$ & 4.78 & 0.09 & \\
\hline 2001-2009 & 130,920 & 4 & 0.77 & 0.61 & 0.98 & 0.03 & $0.00 \%$ & 2.55 & 0.59 & \\
\hline$\geq 2010$ & $6,966,117$ & 3 & 0.99 & 0.97 & 1.01 & 0.38 & $0.00 \%$ & 1.95 & 0.38 & \\
\hline
\end{tabular}

Abbreviations: $N$ number of studies; $N A$ not available.

such as cortisol, have been found to be pronounced in men when compared to women $[55,56]$. Increased cortisol production has been linked to higher rate of morbidity and poorer health outcomes [8]. In addition, HPA axis can mediate the production of sex hormones [57]. In women, estrogen can protect women against heart disease by reducing circulatory levels of harmful cholesterol [58], whereas testosterone increased the concentrations of low-density lipoprotein and inflammatory markers that can drive the progression of atherosclerosis and stroke [59-61] in men. Further, there is evidence that women have stronger immune systems, in part because testosterone caused immunosuppression and more frequently infection $[60,62]$.

From a psychological perspective, women who provide more social support to others and are more engaged in their social networks are shown to be buffered or at least better equipped to deal with stress. The New England
Research Institute reported that $66 \%$ of men rely on their wives for their primary social supports [63]. Men living alone are more likely to disregard professional's advice [64], have smaller and less intimate social networks, are more likely to be lonely and suffer depression than women with similar partner histories $[65,66]$.

From a social behavioral perspective, the social conditioning process may contribute to the influence on marital status in male's increased risk of mortality. Indeed, married men fare better than those who have never been or were previously married. In most Western cultures, boys and young men are often conditioned to feel they are responsible for providing financially for a family. A lack of adherence to this gender norm may result in feelings of perceived hopelessness or inadequacy that impact physical health. For those men who were previously married, there is some evidence that the association between marital status and mortality is largely explained 
by the length of marriage and early life history such as childhood disadvantage [25]. Taken together, this suggests that a life course approach is required to understand the link between marriage and mortality risk.

In comparison with most men who had a more sedentary lifestyle [67-70], adult women under the age of 65 who were reported more doctor visits and go to gym more often than men, with the gender difference widest among individuals aged 18-44 [71]. Moreover, men who drink more alcohol and more smoking than women [72] were 4.5 times as likely to die from CHD in middle age [73] and twice from cirrhosis [74, 75] and more vulnerable to respiratory illnesses, such as COPD and lung cancer, and had more excess risk of death from these diseases.

Our results provide a social context in which to consider why sex-specific differences in individual level risk factors may exist. Recently, traditional CVD-related risk factors, such as smoking and diabetes have been demonstrated to confer greater excess risk of CHD and stroke for women than men. For example, both American Heart Association guidelines and European Society of Cardiology guidelines recommended that women with diabetes should exercise more to counteract the higher excess risk of CVD conferred by diabetes in women than that in men [76-78]. If women do not appear to benefit from marriage to the extent of their male counterparts, this needs to be considered. Low marital quality appears to be linked to women's health behaviors and disease markers including low HDL cholesterol, high triglycerides, and higher BMI, blood pressure and is also a risk factor for recurrent heart attack [79]. Expectations of women as mothers and wives as they relate to caregiving and parenting places them a higher risk of non-fatal CHD in middle age [80]. Our findings that men yield greater mortality risk owing to the absence of marriage support the idea that they have more to lose from marriage dissolution or from never marrying when compared with women who do not attract such a mortality benefit.

\section{Strengths and limitations}

Strengths of this study included the use of a large sample to evaluate sex difference between marital status and cause-specific outcomes. This is advantageous as it can minimize the role of confounding factors. However, several of these issues remain. The meta-analysis was based on prospective cohort studies, therefore, the conventional problems of confounding effects and potential bias in observational study were inevitable. Although our study had a large sample size and for each study we used the estimates from the multiple-adjusted models, which could reduce the confounding and bias, the possible influence of other risk factors could not be ruled out and we are unable to determine causation. Secondly, although we were not able to adjust properly for baseline differences in confounding factors both between and within studies which may explain the small difference observed in our meta-analysis, the sensitivity and subgroup analyses were used to assess the disparities in all the subgroups, and moreover the meta-regression was also performed to evaluate and reduce the heterogeneity among the studies. Thirdly, further sub-categories of marriage or intimate partnerships remained unexamined in this study. For example, marriages with high levels of dissatisfaction and/or conflict may produce poor health outcomes (as has been shown for women especially); long term partnerships that are not officially defined under the traditional definition of marriage may confer positive health benefits particularly through long term cohabitation; the role of children in the marriage and their effect of health requires further exploration. Fourthly, there was an evidence of publication bias for all-cause mortality in widowed and divorced/separated groups, for CVD mortality in never married group and stroke mortality in widowed group. Although the use of trim and fill procedures did not result in the change of the results of our meta-analysis, the possibility of an artifact of unpublished negative studies could not be ignored with this method. Fifthly, these included studies only involved papers published in English language, although publication bias was analyzed, lack of papers published in other language except English limited more in-depth analyses than were reported here.

\section{Conclusion}

Unmarried men (divorced, widowed or never married) have excess risk of stroke mortality and all-cause mortality compared to women. Moreover, men whose marriages were dissolved had higher risk of both cancer and CVD mortality. Compared to their single female counterparts, single men were at higher risk of stroke mortality. Our results also warrant consideration as to why women do not appear to benefit from marriage to the same extent as men. Further studies are warranted to clarify the biological, behavioral, or social mechanisms that may drive these associations in order to make conclusions about its application to public health policy and allocation of public health resources.

\section{Supplementary information}

Supplementary information accompanies this paper at https://doi.org/10. 1186/s41256-020-00133-8.

Additional file 1 Supplemental Table 1. PRISMA 2009 Checklist Supplemental Table 2. Quality of included studies assessed with Newcastle-Ottawa Scale. Supplemental Table 3. Subgroup analyses of women-to-men ratio of relative risks for all-cause mortality associated with marital status. Supplemental Figure 1. Sex-specific relative risks 
(RRs) for all-cause mortality, comparing widowed, divorced/separated and never married to married people: (a) Sex-specific RRs for all-cause mortality, comparing widowed to married people; (b) Sex-specific RRs for allcause mortality, comparing divorced/separated to married people; (c) Sex-specific RRs for all-cause mortality, comparing never married to married people. Supplemental Figure 2. Women-to-men ratios of relative risks (RRRs) for all-cause mortality comparing widowed, divorced/separated and never married to married people: (a) Women-to-men RRRs for all-cause mortality comparing widowed to married people; (b) Womento-men RRRs for all-cause mortality comparing divorced/separated to married people; (c) Women-to-men RRRs for all-cause mortality comparing never married to married people. Supplemental Figure 3. Sexspecific relative risks (RRs) for cancer mortality, comparing non-married, widowed, divorced/separated and never married to married people: (a) Sex-specific RRs for cancer mortality, comparing non-married to married people: (b) Sex-specific RRs for cancer mortality, comparing widowed to married people; (c) Sex-specific RRs for cancer mortality, comparing divorced/separated to married people; (d) Sex-specific RRs for cancer mortality, comparing never married to married people. Supplemental

Figure 4. Women-to-men ratios of relative risks (RRRs) for cancer mortality comparing non-married, widowed, divorced/separated and never married to married people: (a) Women-to-men RRRs for cancer mortality comparing non-married to married people; (b) Women-to-men RRRs for cancer mortality comparing widowed to married people; (c) Women-tomen RRRs for cancer mortality comparing divorced/separated to married people; (d) Women-to-men RRRs for cancer mortality comparing never married to married people. Supplemental Figure 5. Sex-specific relative risks (RRs) for cardiovascular (CV) mortality, comparing non-married, widowed, divorced/separated and never married to married people: (a) Sex-specific RRs for CV mortality, comparing non-married to married people; (b) Sex-specific RRs for CV mortality, comparing widowed to married people; (c) Sex-specific RRs for CV mortality, comparing divorced/separated to married people; (d) Sex-specific RRs for CV mortality, comparing never married to married people. Supplemental Figure 6. Women-tomen ratios of relative risks (RRRs) for cardiovascular (CV) mortality comparing non-married, widowed, divorced/separated and never married to married people: (a) Women-to-men RRRs for CV mortality comparing non-married to married people; (b) Women-to-men RRRs for CV mortality comparing widowed to married people; (c) Women-to-men RRRs for CV mortality comparing divorced/separated to married people; (d) Womento-men RRRs for CV mortality comparing never married to married people. Supplemental Figure 7. Sex-specific relative risks (RRs) for coronary heart disease (CHD) mortality, comparing non-married, widowed, divorced/separated and never married to married people: (a) Sex-specific RRs for CHD mortality, comparing non-married to married people; (b) Sex-specific RRs for CHD mortality, comparing widowed to married people; (c) Sex-specific RRs for CHD mortality, comparing divorced/separated to married people; (d) Sex-specific RRs for CHD mortality, comparing never married to married people. Supplemental Figure 8. Womento-men ratios of relative risks (RRRs) for coronary heart disease (CHD) mortality comparing non-married, widowed, divorced/separated and never married to married people: (a) Women-to-men RRRs for CHD mortality comparing non-married to married people; (b) Women-to-men RRRs for CHD mortality comparing widowed to married people; (c) Women-tomen RRRs for CHD mortality comparing divorced/separated to married people; (d) Women-to-men RRRs for CV mortality comparing never married to married people. Supplemental Figure 9. Sex-specific relative risks (RRs) for stroke mortality, comparing non-married, widowed, divorced/separated and never married to married people: (a) Sex-specific RRs for stroke mortality, comparing non-married to married people; (b) Sex-specific RRs for stroke mortality, comparing widowed to married people; (c) Sex-specific RRs for stroke mortality, comparing divorced/separated to married people; (d) Sex-specific RRs for stroke mortality, comparing never married to married people. Supplemental Figure $\mathbf{1 0 .}$

Women-to-men ratios of relative risks (RRRs) for stroke mortality comparing non-married, widowed, divorced/separated and never married to married people: (a) Women-to-men RRRs for stroke mortality comparing non-married to married people; (b) Women-to-men RRRs for stroke mortality comparing widowed to married people; (c) Women-to-men RRRs for stroke mortality comparing divorced/separated to married people; (d)
Women-to-men RRRs for stroke mortality comparing never married to married people. Supplemental Figure 11. Meta-regression for mean age at baseline for pooled women-to-men ratios of relative risk for risk of all-cause mortality comparing non-married people to married people. Supplemental Figure 12. Subgroup analyses for all-cause mortality for pooled women-to-men ratios of relative risk (RRRs) for risk of all-cause mortality comparing widowed people to married people. Supplemental Figure 13. Begg's publication bias plot for the pooled ratio of womento-men relative risks: (a) Begg's publication bias plot for CHD mortality in divorced/separated group; (b) Begg's publication bias plot for all-cause mortality in widowed group; (c) Begg's publication bias plot for all-cause mortality in never married group; Abbreviations: CHD: coronary heart disease; RR: relative risk; RRR: ratio of RR.

\section{Acknowledgements}

Not applicable.

\section{Authors' contributions}

Conception and design of the study: YW, YJ and CY. Acquisition of data and analysis: YW, YJ, and JH. Statistical analysis: YJ and YW. Writing and revision of the manuscript: $Y W, Y J, J N, A O, W H, L Z, J H, H L, Y Z, C Y$, and $M W$. The author(s) read and approved the final manuscript.

\section{Funding}

This work was supported by the National Natural Science Foundation of China (Grant NO.81773552) and the National Key R\&D Program of China (Grant No. 2018YFC1315302 and 2017YFC 1200502).

\section{Availability of data and materials}

The following information was supplied regarding data availability: This is a systematic review of the literature. No raw data was analysed.

\section{Ethics approval and consent to participate}

Not applicable.

\section{Consent for publication}

Not applicable.

\section{Competing interests}

The authors declare that they have no competing interests.

\section{Author details}

'Department of Epidemiology and Biostatistics, School of Health Sciences, Wuhan University, 185 Donghu Road, Wuchang District, Wuhan 430071, China. ${ }^{2}$ Department of endocrinology, The Second Hospital of Shanxi Medical University, Taiyuan, China. ${ }^{3}$ Department of Sociology \& Institute for Empirical Social Science Research, School of Humanities and Social Sciences, Xi'an Jiaotong University, Xi'an, China. ${ }^{4}$ Melbourne School of Population and Global Health, University of Melbourne, Carlton, Australia. ${ }^{5}$ School of Nursing, Guangdong Pharmaceutical University, Guangzhou, China. ${ }^{6}$ Shanghai Institute of Cardiovascular Diseases, Zhongshan Hospital of Fudan University, Shanghai, China. ${ }^{7}$ Faculty of Psychology, Beijing Normal University, Beijing, China. ${ }^{8}$ Department of Ophthalmology, The First People's Hospital of Xianyang City, Xianyang, China. ${ }^{9}$ The George Institute for Global Health, University of Oxford, Oxford, UK. ${ }^{10}$ The George Institute for Global Health, University of New South Wales, Sydney, Australia. ${ }^{11}$ Department of Epidemiology, Johns Hopkins University, Baltimore, MD, USA.

Received: 17 October 2019 Accepted: 12 February 2020

Published online: 28 February 2020

\section{References}

1. Tatangelo G, McCabe M, Campbell S, Szoeke C. Gender, marital status and longevity. Maturitas. 2017;100:64-9. https://doi.org/10.1016/j.maturitas.2017. 03.002 .

2. American Census Bureau. Number of single-person households in the U.S. from 1960 to 2017 (in millions). 2017. https://www.statista.com/statistics/242 022/number-of-single-person-households-in-the-us/. Accessed 21 Sept 2019.

3. National Bureau of Statistics. China statistical yearbook 2017. http://www. xiaze.org/2017/. Accessed 21 Sept 2019. 
4. Waite LJJD. Does marriage matter? Demography. 1995;32:483-507.

5. Hu YR, Goldman NJD. Mortality differentials by marital status: an international comparison. Demography. 1990;27:233-50.

6. Wyke S, Ford G. Competing explanations for associations between marital status and health. Soc Sci Med. 1992;34:523-32.

7. Umberson D. Gender, marital status and the social control of health behavior. Soc Sci Med. 1992;34:907-17.

8. Chin B, Murphy MLM, Janicki-Deverts D, Cohen S. Marital status as a predictor of diurnal salivary cortisol levels and slopes in a community sample of healthy adults. Psychoneuroendocrinology. 2017;78:68-75. https://doi.org/10.1016/j.psyneuen.2017.01.016.

9. Matthews K, Schwartz J, Cohen S, Seeman T. Diurnal cortisol decline is related to coronary calcification: CARDIA study. Psychosom Med. 2006;68: 657-61.

10. Dekker MJ, Koper JW, Aken MOV, et al. Salivary cortisol is related to atherosclerosis of carotid arteries. J Clin Endocrinol Metab. 2008;93:3741-7. https://doi.org/10.1210/jc.2008-0496.

11. Sephton SE, Sapolsky RM, Kraemer HC, Spiegel D. Diurnal cortisol rhythm as a predictor of breast cancer survival. J Natl Cancer Inst. 2013;30:S163-S70.

12. Sephton SE, Lush E, Dedert EA, et al. Diurnal cortisol rhythm as a predictor of lung cancer survival. J Natl Cancer Inst. 2000;92:994-1000. https://doi.org/ 10.1016/j.bbi.2012.07.019

13. Anagnostis P, Athyros VG, Tziomalos K, Karagiannis A, Mikhailidis DP. Clinical review: the pathogenetic role of cortisol in the metabolic syndrome: a hypothesis. J Clin Endocrinol Metab. 2009;94:2692-701. https://doi.org/10. 1210/jc.2009-0370

14. Brunner EJ, Hemingway H, Walker BR, et al. Adrenocortical, autonomic, and inflammatory causes of the metabolic syndrome. Circulation. 2002;106: 2659-65.

15. Stringhini S, Carmeli C, Jokela M, et al. Socioeconomic status and the $25 \times$ 25 risk factors as determinants of premature mortality: a multicohort study and meta-analysis of 1.7 million men and women. Lancet. 2017:389:122937. https://doi.org/10.1016/S0140-6736(16)32380-7.

16. Brunner E. Commentary: education, education, education. Int J Epidemiol. 2001;30:1126-8.

17. Leong DP, Joseph PG, Mckee M, et al. Reducing the global burden of cardiovascular disease, part 2: prevention and treatment of cardiovascular disease. Circ Res. 2017:121:695. https://doi.org/10.1161/CIRCRESAHA.117. 311849

18. Beauchamp A, Peeters A, Wolfe R, et al. Inequalities in cardiovascular disease mortality: the role of behavioural, physiological and social risk factors. J Epidemiol Community Health. 2010;64:542-8. https://doi.org/10.1136/jech. 2009.094516.

19. Wong CW, Kwok CS, Narain A, et al. Marital status and risk of cardiovascular diseases: a systematic review and meta-analysis. Heart. 2018. https://doi.org/ 10.1136/heartjnl-2018-313005.

20. Eaker ED, Sullivan LM, Kellyhayes M, D'Agostino RB Sr, Benjamin E. Marital status, marital strain, and risk of coronary heart disease or total mortality: the Framingham offspring study. Psychosom Med. 2007:69:509.

21. Breeze E, Sloggett A, Fletcher A. Socioeconomic and demographic predictors of mortality and institutional residence among middle aged and older people: results from the longitudinal study. J Epidemiol Community Health. 1999;53:765-74.

22. Fuhrer R, Dufouil C, Antonucci TC, et al. Psychological disorder and mortality in French older adults: do social relations modify the association? Am J Epidemiol. 1999;149:116-26.

23. Robards J, Evandrou M, Falkingham J, Vlachantoni A. Marital status, health and mortality. Maturitas. 2012;73:295-9. https://doi.org/10.1016/j.maturitas. 2012.08.007.

24. Manzoli L, Villari P, Pirone GM, Boccia A. Marital status and mortality in the elderly: a systematic review and meta-analysis. Soc Sci Med. 2007;64:77-94. https://doi.org/10.1016/j.socscimed.2006.08.031.

25. Kilpi $F$, Konttinen $H$, Silventoinen $K$, Martikainen $P$. Living arrangements as determinants of myocardial infarction incidence and survival: a prospective register study of over 300,000 Finnish men and women. Soc Sci Med. 2015; 133:93-100. https://doi.org/10.1016/.socscimed.2015.03.054

26. Stroup DF, Berlin JA, Morton SC, et al. Meta-analysis of observational studies in epidemiology: a proposal for reporting. Meta-analysis of observational studies in epidemiology (MOOSE) group. JAMA. 2000;283:2008-12.

27. GA Wells, B Shea, D O'Connell, et al. The Newcastle-Ottawa Scale (NOS) for assessing the quality of nonrandomized studies in meta-analyses http://
www.evidencebasedpublichealth.de/download/Newcastle_Ottowa_Scale_ Pope_Bruce.pdf. Accessed 20 Sept 2019.

28. Huxley R, Barzi F, Woodward M. Excess risk of fatal coronary heart disease associated with diabetes in men and women: meta-analysis of 37 prospective cohort studies. BMJ. 2006;332:73-6. https://doi.org/10.1136/bmj. 38678.389583.7C

29. Higgins JP, Thompson SG. Quantifying heterogeneity in a meta-analysis. Stat Med. 2002;21:1539-58.

30. Higgins JP, Thompson SG, Deeks JJ, Altman DG. Measuring inconsistency in meta-analyses. BMJ. 2003;327:557-60. https://doi.org/10.1136/bmj.327.7414. 557.

31. Duval S, Tweedie R. Trim and fill: a simple funnel-plot-based method of testing and adjusting for publication bias in meta-analysis. Biometrics. 2015; 56:455-63.

32. Va P, Yang WS, Nechuta $S$, et al. Marital status and mortality among middle age and elderly men and women in urban Shanghai. PLoS One. 2011;6: e26600. https://doi.org/10.1371/journal.pone.0026600.

33. Frisch M, Simonsen J. Marriage, cohabitation and mortality in Denmark: national cohort study of 6.5 million persons followed for up to three decades (1982-2011). Int J Epidemiol. 2013;42:559-78. https://doi.org/10 1093/ije/dyt024.

34. Nilsson PM, Johansson SE, Sundquist J. Low educational status is a risk factor for mortality among diabetic people. Diabet Med. 1998:15:213-9.

35. Molloy GJ, Stamatakis E, Randall G, et al. Marital status, gender and cardiovascular mortality: Behavioural, psychological distress and metabolic explanations. Soc Sci Med. 2009;69:223-8. https://doi.org/10.1016/j. socscimed.2009.05.010

36. Dupre ME, Beck AN, Meadows SO. Marital trajectories and mortality among US adults. Am J Epidemiol. 2009;170:546. https://doi.org/10.1093/aje/ kwp194.

37. Scafato E, Galluzzo L, Gandin C, et al. Marital and cohabitation status as predictors of mortality: a 10-year follow-up of an Italian elderly cohort. Soc Sci Med. 2008;67:1456-64. https://doi.org/10.1016/j.socscimed.2008.06.026.

38. Stimpson JP, Kuo YF, Ray LA, Raji MA, Peek MK. Risk of mortality related to widowhood in older Mexican Americans. Ann Epidemiol. 2007;17:313-9.

39. Ikeda A, Iso H, Toyoshima $\mathrm{H}$, et al. Marital status and mortality among Japanese men and women: the Japan collaborative cohort study. BMC Public Health. 2007:7:1-7.

40. Smith KR, Waitzman NJ. Effects of marital status on the risk of mortality in poor and non-poor neighborhoods. Ann Epidemiol. 1997;7:343-9.

41. Jaffe DH, Eisenbach Z, Neumark YD, Manor O. Individual, household and neighborhood socioeconomic status and mortality: a study of absolute and relative deprivation. Soc Sci Med. 2005;60:989-97.

42. Nilsson PM, Nilsson JA, Ostergren PO, Berglund G. Social mobility, marital status, and mortality risk in an adult life course perspective: the Malmö preventive project. Scand J Public Health. 2005;33:412.

43. Hurt LS, Ronsmans CS, Saha S. Effects of education and other socioeconomic factors on middle age mortality in rural Bangladesh. J Epidemiol Community Health. 2004:58:315-20.

44. Strand BH, Tverdal A. Can cardiovascular risk factors and lifestyle explain the educational inequalities in mortality from ischaemic heart disease and from other heart diseases? 26 year follow up of 50000 Norwegian men and women. J Epidemiol Community Health. 2004:58:705-9.

45. Malyutina S, Bobak M, Simonova G, et al. Education, marital status, and total and cardiovascular mortality in Novosibirsk, Russia: a prospective cohort study. Ann Epidemiol. 2004;14:244-9.

46. Nagata C, Takatsuka N, Shimizu H. The impact of changes in marital status on the mortality of elderly Japanese. Ann Epidemiol. 2003;13(4):218-22.

47. Johnson NJ, Backlund E, Sorlie PD, Loveless CA. Marital status and mortality: the national longitudinal mortality study. Ann Epidemiol. 2000;10:224-38.

48. Iwasaki M, Otani T, Sunaga R, et al. Social networks and mortality based on the Komo-Ise cohort study in Japan. Int J Epidemiol. 2002:31:1208-18.

49. Robles TF, Kiecolt-Glaser JK. The physiology of marriage: pathways to health Physiol Behav. 2003:79:409-16.

50. Zhang Z, Mark D. Hayward. gender, the marital life course, and cardiovascular disease in late midlife. J Marriage Fam. 2010;68:639-57.

51. Yan $X Y$, Huang $S M$, Huang $C Q$, Wu WH, Qin Y. Marital status and risk for late life depression: a meta-analysis of the published literature. J Int Med Res. 2011;39:1142. https://doi.org/10.1177/147323001103900402.

52. Huang MF, Yen CF, Lung FW. Moderators and mediators among panic, agoraphobia symptoms, and suicidal ideation in patients with panic 
disorder. Compr Psychiatry. 2010;51:243-9. https://doi.org/10.1016/j. comppsych.2009.07.005.

53. Goldman NJD. Marriage selection and mortality patterns: inferences and fallacies. Demography. 1993;30:189-208.

54. Manfredini R, De GA, Tiseo R, et al. Marital status, cardiovascular diseases, and cardiovascular risk factors: a review of the evidence. J Women's Health (Larchmt). 2017;26:624-32. https://doi.org/10.1089/jwh.2016.6103.

55. Kajantie E, Phillips DIJP. The effects of sex and hormonal status on the physiological response to acute psychosocial stress. Psychoneuroendocrinology. 2006;31:151-78. https://doi.org/10.1016/j. psyneuen.2005.07.002.

56. Kudielka BM, Kirschbaum C. Sex differences in HPA axis responses to stress: a review. Biol Psychol. 2005;69:113-32. https://doi.org/10.1016/j.biopsycho. 2004.11.009.

57. Verma R, Balhara YP, Gupta CS. Gender differences in stress response: role of developmental and biological determinants. Ind Psychiatry J. 2012;20:4-10. https://doi.org/10.4103/0972-6748.98407.

58. Yang XP, Reckelhoff JF. Estrogen, hormonal replacement therapy and cardiovascular disease. Curr Opin Nephrol Hypertens. 2012;20:133-8. https:// doi.org/10.1097/MNH.0b013e3283431921.

59. Wang X, Smith Gl, Patterson BW, et al. Testosterone increases the muscle protein synthesis rate but does not affect very-low-density lipoprotein metabolism in obese premenopausal women. Am J Physiol Endocrinol Metab. 2012;302:E740-6. https://doi.org/10.1152/ajpendo.00533.2011.

60. Engström G, Hedblad B, Rosvall M, Janzon L, Lindgärde F. Occupation, marital status, and low-grade inflammation: mutual confounding or independent cardiovascular risk factors? Arterioscler Thromb Vasc Biol. 2006; 26:643-8. https://doi.org/10.1161/01.ATV.0000200100.14612.bb.

61. Evans MR, Goldsmith AR. The effects of testosterone on antibody production and plumage coloration in male house sparrows (Passer domesticus). Behav Ecol Sociobiol. 2000;47:156-63.

62. Pinheiro AO, Pereira VL Jr, Baltatu OC, Campos LA. Cardiac autonomic dysfunction in elderly women with myocardial infarction. Curr Med Res Opin. 2015;31:1849-54. https://doi.org/10.1185/03007995.2015.1074065.

63. Listed N. Marriage and men's health. Harv Mens Health Watch. 2010;14:1-3.

64. Addis ME, Mahalik JR. Men, masculinity, and the contexts of help seeking. Am Psychol. 2003;58:5-14.

65. Kendler KS, Myers J, Prescott CA. Sex differences in the relationship between social support and risk for major depression: a longitudinal study of opposite-sex twin pairs. Am J Psychiatry. 2005;162:250-6. https://doi.org/ 10.1176/appi.ajp.162.2.250.

66. Staehelin K, Schindler C, Spoerri A, Zemp Stutz E. Swiss National Cohort Study Group. Marital status, living arrangement and mortality: does the association vary by gender? J Epidemiol Community Health. 2012;66:e22. https://doi.org/10.1136/jech.2010.128397.

67. Gross SM, Gary TL, Browne DC, LaVeist TA. Gender differences in body image and health perceptions among graduating seniors from a historically black college. J Natl Med Assoc. 2005;97:1608-19.

68. Mccreary DR, Sadava SW. Gender differences in relationships among perceived attractiveness, life satisfaction, and health in adults as a function of body mass index and perceived weight. Psychol Men Masculinity. 2001;2: $108-16$

69. Costa MG, Petrucci GD, Lessa HB. Change in body weight and body image in young adults: a longitudinal study. BMC Public Health. 2015;15:1-7. https://doi.org/10.1186/s12889-015-1579-7.

70. O'Neil A, Scovelle AJ, Milner AJ, Kavanagh A. Gender/sex as a social determinant of cardiovascular risk. Circulation. 2018;137:854-64. https://doi. org/10.1161/CIRCULATIONAHA.117.028595.

71. Redondo-Sendino Á, Guallar-Castillón P, Banegas JR, Rodríguez-Artalejo F. Gender differences in the utilization of health-care services among the older adult population of Spain. BMC Public Health. 2006;6:1-9. https://doi. org/10.1186/1471-2458-6-155.

72. Wilsnack RW, Wilsnack SC, Kristjanson AF, Vogeltanz-Holm ND, Gmel G. Gender and alcohol consumption: patterns from the multinational GENACIS project. Addiction. 2010;104:1487-500. https://doi.org/10.1111/j.1360-0443. 2009.02696.x

73. Bots SH, Peters SAE, Woodward M. Sex differences in coronary heart disease and stroke mortality: a global assessment of the effect of ageing between 1980 and 2010. BMJ Glob Health. 2017;2:e000298. https://doi.org/10.1136/ bmjgh-2017-000298.
74. Pan JJ, Fallon MB. Gender and racial differences in nonalcoholic fatty liver disease. World J Hepatol. 2014;6:274-83. https://doi.org/10.4254/wjh.v6.15.274

75. Yeluru A, Nguyen P, Le AK, et al. Gender differences in outcomes of cirrhosis in a large cohort of patients in the United States. Gastroenterology. 2017;152:S1142. https://doi.org/10.1016/50016-5085(17)33835-0 Accessed 18 Sept 2019.

76. Perreault L, Ma Y, Dagogo-Jack S, et al. Sex differences in diabetes risk and the effect of intensive lifestyle modification in the diabetes prevention program. Diabetes Care. 2008;31:1416-21. https://doi.org/10.2337/dc07-2390.

77. RydeN L, Grant PJ, Anker SD, et al. ESC guidelines on diabetes, pre-diabetes and diseases of the cardiovascular system developed in cooperation with the EASD. Kardiol Pol. 2013;71(Suppl 11(XI)):S319-94. https://doi.org/10. 5603/KP.2013.0289.

78. Regensteiner JG, Golden S, Huebschmann AG, et al. Sex differences in the cardiovascular consequences of diabetes mellitus: a scientific statement from the American Heart Association. Circulation. 2015;132:2424-47. https:/ doi.org/10.1161/CIR.0000000000000343.

79. Orth-Gomer K, Wamala SP, Horsten M, et al. Marital stress worsens prognosis in women with coronary heart disease: the Stockholm female coronary risk study. JAMA. 2000;284:3008-14.

80. Lyons JG, Cauley JA, Fredman L. The effect of transitions in caregiving status and intensity on perceived stress among 992 female caregivers and noncaregivers. J Gerontol A Biol Sci Med Sci. 2015;70:1018-23. https://doi. org/10.1093/gerona/glv001.

\section{Ready to submit your research? Choose BMC and benefit from:}

- fast, convenient online submission

- thorough peer review by experienced researchers in your field

- rapid publication on acceptance

- support for research data, including large and complex data types

- gold Open Access which fosters wider collaboration and increased citations

- maximum visibility for your research: over $100 \mathrm{M}$ website views per year

At BMC, research is always in progress.

Learn more biomedcentral.com/submissions 